\title{
Rubella transmission and the risk of congenital rubella syndrome in Liberia: a need to introduce rubella-containing vaccine in the routine immunization program
}

Abyot Bekele Woyessa ${ }^{1 *}$ (D), Mohammed Seid Ali ${ }^{1}$, Tiala K. Korkpor ${ }^{1}$, Roland Tuopileyi II ${ }^{1}$, Henry T. Kohar ${ }^{2}$, John Dogba ${ }^{3}$, April Baller', Julius Monday', Suleman Abdullahi', Thomas Nagbe, Gertrude Mulbah', Mohammed Kromah', Jeremy Sesay ${ }^{1}$, Kwuakuan Yealue', Tolbert Nyenswah ${ }^{3}$ and Mesfin Zbelo Gebrekidan ${ }^{1}$

\footnotetext{
Abstract

Background: Rubella is an RNA virus in the genus Rubivirus within the Matonaviridae family. Rubella remains a leading vaccine-preventable cause of birth defects. Most African countries including Liberia do not currently provide rubella-containing vaccine (RCV) in their immunization program. We analyzed the existing surveillance data to describe rubella cases and identify the at-risk population.

Methods: We conducted a retrospective descriptive statistics on the suspected-measles case-based surveillance data that obtained from the national database. Suspected-measles cases who were negative and indeterminate for measles IgM and tested for rubella lgM were extracted from the database. We used only rubella IgM positive cases to calculate trends and percentages by person, place and time. The cumulative-percent curve was used to visually describe the age distribution of rubella cases.

Results: During 2017-2018, a total of 2027 suspected-measles cases with known laboratory results were reported; of which, 1307 were tested for rubella IgM. Among tested cases, 472 (36\%) were positive, 769 (59\%) were negative and 66 (5\%) were indeterminate for rubella IgM. Female contributed 269 (57\%) of the confirmed rubella cases respectively. The median age was 7 years with an interquartile range of 5-10 years. From the total rubella cases, 6 (1\%) were under 1 year, 109 (23\%) were 1-4 years, 207 (44\%) were 5-9years, 87 (18\%) were 10-14 years and 56 $(12 \%)$ were more than or equal to 15 years. Women in their reproductive-age contributed $23(5 \%)$ of rubella cases with $17 \%$ positivity rate. Two-thirds or 307 (65\%) of the cases were reported from February to May which is dry season in Liberia.

\footnotetext{
* Correspondence: abyotbekelephem@gmail.com

${ }^{1}$ World Health Organization Country office for Liberia, Monrovia, Liberia

Full list of author information is available at the end of the article
}

(c) The Author(s). 2019 Open Access This article is distributed under the terms of the Creative Commons Attribution 4.0 International License (http://creativecommons.org/licenses/by/4.0/), which permits unrestricted use, distribution, and reproduction in any medium, provided you give appropriate credit to the original author(s) and the source, provide a link to the Creative Commons license, and indicate if changes were made. The Creative Commons Public Domain Dedication waiver (http://creativecommons.org/publicdomain/zero/1.0/) applies to the data made available in this article, unless otherwise stated. 
(Continued from previous page)

Conclusions: Our analysis revealed that rubella was widely circulating in Liberia. Majority of the cases were reported among children < 15 years. However, rubella was also reported among women of reproductive age and infants $<1$ year with no report of congenital rubella syndrome (CRS). Detail investigation of rubella cases among infants of $<1$ year and women of reproductive age is important to uncover CRS. Establishment of CRS surveillance and the introduction of RCV in the immunization program are crucial to prevent rubella infection and avert the risk of CRS.

Keywords: Rubella, Measles case-based surveillance, Women of childbearing age, Epidemiology, Pre-vaccine era, Liberia, West Africa

\section{Background}

Rubella is an RNA virus belongs to Rubivirus genus within the Matonaviridae family [1] . The rubella virus is a human disease with no known animal reservoir and transmits to a healthy person through air droplet shed when an infected person sneezes or coughs [2]. Rubella symptoms are usually mild, and up to $50 \%$ of infections may be clinically in-apparent [3]. An Infected person is infectious and transmits the virus to healthy people starting 7 days before to 7 days after the onset of rash [4]. Infection occurs a few weeks before conception and in early pregnancy especially during the first trimester may result in miscarriage, fetal death, or congenital deformities known as congenital rubella syndrome (CRS) $[5,6]$.

The likelihood of CRS is high, 90\%, among infants born from mothers infected by rubella virus during their early pregnancy [7]. Globally, an estimation of 100,000 babies is born with CRS every year $[8,9]$. CRS incidence rate varies from 0.1-0.2 during an endemic and 0.8-4 during an epidemic per 1000 live births $[6,10]$. An infant with CRS or congenital rubella infection (CRI) sheds live rubella virus for a prolonged time [11].

Regardless of the availability of safe and effective vaccine, rubella virus remains a leading vaccinepreventable cause of birth defects, especially in developing countries [6, 12]. As of 2009, only $130(67 \%)$ of global and 2 (4\%) of African countries introduced rubella-containing vaccine $(\mathrm{RCV})$ in their routine immunization programs $[13,14]$. As of $2017,84 \%$ of the World Health Organization (WHO) member countries introduced rubella-containing vaccine in their program, whereas member countries in Africa region lack largely [15]. Following the introduction of rubella vaccine in many countries, global rubella vaccination coverage increased from $26 \%$ in 2007 to $52 \%$ in 2017 [16] and reported rubella cases declined by $97 \%$, from 670,894 cases in 2000 to 22,361 cases in 2016 [17]. Rubella cases reduction mostly documented in countries providing rubella vaccine $[12,18]$. In Africa, the rubella virus is still widely circulating with limited evidence of CRS [19]. Rubella incidence decreased by $48-96 \%$ in five countries in the Africa region in the post RCV introduction period as compared to the average incidence in the years before vaccine introduction [20]. To prevent rubella and CRS all WHO member countries are expected to introduce rubella vaccine in routine immunization program and reach more than $90 \%$ coverage at the national and $80 \%$ at the district level by 2020 [21].

In Liberia, an expanded program on immunization (EPI) was first launched in 1978 in accordance with WHO recommendation to all member countries. EPI have implemented in all counties and districts of Liberia as per the WHO recommendations. Children less than 1 year, as well as women of childbearing age and pregnant women, are the target groups for routine immunization. Currently, Bacillus Calmette-Guérin (BCG), pentavalent vaccine (Tetanus, Haemophilus Influenza, Diphtheria, Pertussis and Hepatitis B), oral polio vaccine (OPV), pneumococcal conjugate vaccine, measles (MCV1), yellow fever vaccine, rota vaccine, and inactivated polio vaccine (IPV) are antigens in immunization schedule for children under 1 year while tetanus toxoid is being given to every woman of childbearing age (14-49 years) in Liberia [22]. However, a rubella-containing vaccine has not yet introduced in the routine immunization program in the country. In Liberia, the routine MCV1 coverage was $80 \%$ in 2016 and $87 \%$ in 2017 according to joint WHO and United Nations Children's Emergency Fund (UNICEF) estimation [23].

In Liberia and in all other African countries, rubella surveillance is integrated into measles case-based surveillance system. The surveillance data is collected according to the national integrated diseases surveillance and response (IDSR) technical guideline using a standard case definition for a suspected-measles case, which is an illness with fever and maculopapular generalized rash and cough, coryza or conjunctivitis or any person in whom a clinician suspects measles [24]. Blood specimen from the first five-ten suspected measles cases collected within 28 days after the onset of rash [24]. The specimens collected by the health facility's laboratory technicians and transported to the national laboratory by a rider for health within $72 \mathrm{~h}$ after collection. The blood specimens are first tested for measles-specific immunoglobulin M (IgM) antibody using 
enzyme-linked immunosorbent assay (ELISA) and in accordance with WHO African region guideline [25] all IgM negative and indeterminate result for measles are further tested for rubella-specific IgM antibody using ELISA technique at the national reference laboratory. In Liberia, the burden, trend and transmission pattern of rubella has not clearly described. Here, we analyzed rubella data obtained from the national measles case-based surveillance database to describe rubella transmission pattern and identify at-risk population to pinpoint and recommend preventive public health interventions.

\section{Methods}

We obtained 2 years, 2017-2018, measles case-based surveillance data from the National Public Health Institute of Liberia (NPHIL). We extracted the suspected-measles cases with known laboratory test results from the database. For this analysis, we used only Laboratory-confirmed rubella IgM positive cases as rubella cases. Descriptive statistics such as count, percentage, median and interquartile range were used to summarize each of the sociodemographic and clinical variables included in the dataset. The cumulative percentage was used to graphically describe the age distribution of rubella cases by sex. We have further categorized rubella cases into five age groups (under 1 year, $1-4$ years, 5-9 years, $10-14$ years and $\geq 15$ years). Rubella IgM positivity rate has calculated by dividing rubella IgM positive cases to total specimens tested for rubella IgM and expressed in 100 in each category. We calculated the annualized rubella incidence rate by dividing the average of the 2 years rubella IgM positive cases to mid-year population and expressed in 100,000. To describe the possible risk of CRS, we separately analyzed rubella among women of childbearing age (15-49 years). Quantum Geographic Information System (QGIS) was used to visually demonstrate district level geographical distribution of rubella cases.

\section{Results}

During 2017-2018, a total of 2027 suspected-measles cases with laboratory result was extracted from the national database; among them, 1307 specimens which were primarily negative and indeterminate for Measles IgM were further tested to detect rubella-specific IgM antibody. Among those tested, 472 (36\%) were positive, 769 (59\%) were negative and 66 (5\%) were indeterminate for rubella IgM (Table 1).

Among the confirmed cases 353 (75\%) were reported in 2017 and $119(25 \%)$ were reported in 2018. Female and male contributed 269 (57\%) and 203 (43\%) confirmed rubella cases respectively. Rubella cases have detected in all age groups with median age 7 years and interquartile ranges $5-10$ years. Among the total rubella cases, 6 (1\%) were under 1 year, $109(23 \%)$ were $1-4$ years, $207(44 \%)$ were $5-9$ years, $87(18 \%)$ were $10-14$ years, $56(12 \%)$ were $\geq 15$ years while the rest $7(1 \%)$ of the cases had no age data. Women in the reproductive age group contributed $23(5 \%)$ of the total rubella cases

Table 1 Laboratory results for rubella-specific immunoglobulin M antibody testing of suspected measles cases, 2017-2018, Liberia

\begin{tabular}{|c|c|c|c|c|c|c|}
\hline \multirow[t]{2}{*}{ Variables } & \multirow{2}{*}{$\begin{array}{l}\text { asuspected } \\
\text { measles } \\
\text { cases }\end{array}$} & \multirow{2}{*}{$\begin{array}{l}{ }^{\text {b Rubella }} \\
\text { lgM } \\
\text { tested }\end{array}$} & \multicolumn{4}{|c|}{ Rubella IgM result } \\
\hline & & & $\overline{\lg M+{ }^{c}(\%)}$ & $\lg M-$ & Indeterminate & ${ }^{\mathrm{d} P o s i t i v i t y} \%$ \\
\hline Total cases & 2027 & 1307 & 472 & 769 & 66 & 36 \\
\hline \multicolumn{7}{|l|}{ Year } \\
\hline 2017 & 1191 & 882 & $353(75)$ & 478 & 51 & 40 \\
\hline 2018 & 836 & 425 & $119(25)$ & 291 & 15 & 28 \\
\hline \multicolumn{7}{|l|}{ Sex } \\
\hline Female & 1050 & 703 & $269(57)$ & 404 & 30 & 38 \\
\hline Male & 977 & 604 & $203(43)$ & 365 & 36 & 34 \\
\hline \multicolumn{7}{|l|}{ Age Group } \\
\hline$<1$ Year & 81 & 37 & $6(1)$ & 29 & 2 & 16 \\
\hline 1-4 Years & 525 & 287 & $109(23)$ & 172 & 6 & 38 \\
\hline 5-9 Years & 647 & 460 & $207(44)$ & 221 & 32 & 45 \\
\hline 10-14 Years & 329 & 249 & $87(18)$ & 145 & 17 & 35 \\
\hline$>14$ Years & 420 & 258 & $56(12)$ & 195 & 7 & 22 \\
\hline NA & 25 & 16 & $7(1)$ & 7 & 2 & 44 \\
\hline Women of Childbearing Age & 211 & 133 & $23(5)$ & 106 & 4 & 17 \\
\hline
\end{tabular}

${ }^{\mathrm{a}}$ Suspected measles cases with known laboratory result, ${ }^{\mathrm{b}}$ suspected measles cases which are negative and indeterminate for measles lgM and tested for Rubella IgM, 'Proportion of confirmed rubella cases from total rubella positive cases in each category, ${ }^{\mathrm{d}}$ Rubella lgM positivity rate was calculated by dividing the number of Rubella IgM positive cases to specimen tested for rubella IgM with specific variables, IgM Immunoglobulin M, NA Not available 
with a positivity rate of $17 \%(23 / 133)$ (Table 1 and Fig. 1).

From the total rubella cases, about two-thirds or 307 (65\%) of them were detected from February to May. The highest cases were detected in February (26\%) followed by March 82 (17\%), April 59 (13\%) and May 45(10\%) while the lowest case was detected from July to October. Similarly, rubella IgM positivity rate was high in February 51\%, April 47\%, and March 39\% and decreased to 15 and 17\% in September and August respectively (Fig. 2).

Rubella cases were reported from all counties of Liberia. Majority of the cases were reported from Montserrado 72 (15.3\%), Lofa 68 (14.3\%) and Margibi 66 (14.0\%) while with the lowest number reported was in Rivercess 6 (1.3\%). The national rubella IgM positivity rate was $36 \%$ which ranged from $14 \%$ in Rivercess County to $48 \%$ in Bomi County (Table 2 and Fig. 3). However, the rubella IgM positive incidence rate was high in Bomi followed by Grand Kru and Margibi (Table 3).

\section{Discussion}

Our analysis uncovered that the rubella disease is circulating widely in Liberia and primarily infected young children under 15 years of age. The study also revealed that the rubella IgM positive cases have also detected among women of childbearing age in 5\% of rubella confirmed cases with $17 \%$ positivity rate among childbearing age groups. Detection of rubella IgM positive cases among women of reproductive age suggested the possibility of rubella infection during pregnancy that could potentially lead to CRS.

The rubella positivity rate $(36 \%)$ in our finding was almost similar to study conducted in Zimbabwe (37.6\%) [27] and high as compared to similar other studies in the African region: for example the rubella IgM positivity rate was $30.2 \%$ in the Central Africa Republic [28], 16.6\% in Côte d'Ivoire [29], 12.1-15.3\% in Ethiopia [29, 30], $10.7 \%$ in Nigeria [31] and in Cameroon 9.3\% [32]. The difference in positivity rate might be attributed to the nature of population settlement, topography, living conditions and study designs.

All age groups were affected while about $90 \%$ of rubella IgM positive cases were found among children under 15 years old which is also similar to other findings in Cameroon [32]. We further observed that the majority of rubella cases were reported among the younger age groups mainly 5-9 years with a median age of 7 years. This finding is similar with the study conducted on prolonged surveillance data from 40 countries in Africa in which $47 \%$ of rubella IgM positive cases detected among children 5-9years old with an interquartile range of 4.2-7 years [19]. Other findings from similar studies demonstrated in Sub-Saharan Africa countries also supported our result [33, 34]. For instance, rubella IgM positive cases contributed $43.5 \%$ in the Central Africa Republic and $43.0 \%$ in the Democratic Republic of Congo in children 5-9 Years [28, 35] which are similar to our result. This might be because of the nature of the surveillance system. As measles surveillance is mainly focused on under 15 years children and rubella in an adult is mostly clinically inapparent, the chance of missing rubella in adult and older age group is high.

In our findings, we observed that about $5 \%$ of $\operatorname{IgM}$ positive rubella cases were attributed to women of childbearing age. This is supported by other similar studies in Africa. The study conducted on measles case-based surveillance data from 40 countries in Sub-Saharan Africa indicated that women of reproductive age contributed $5 \%$ of all rubella positive cases which is comparable with our finding [19]. In the Democratic Republic of Congo

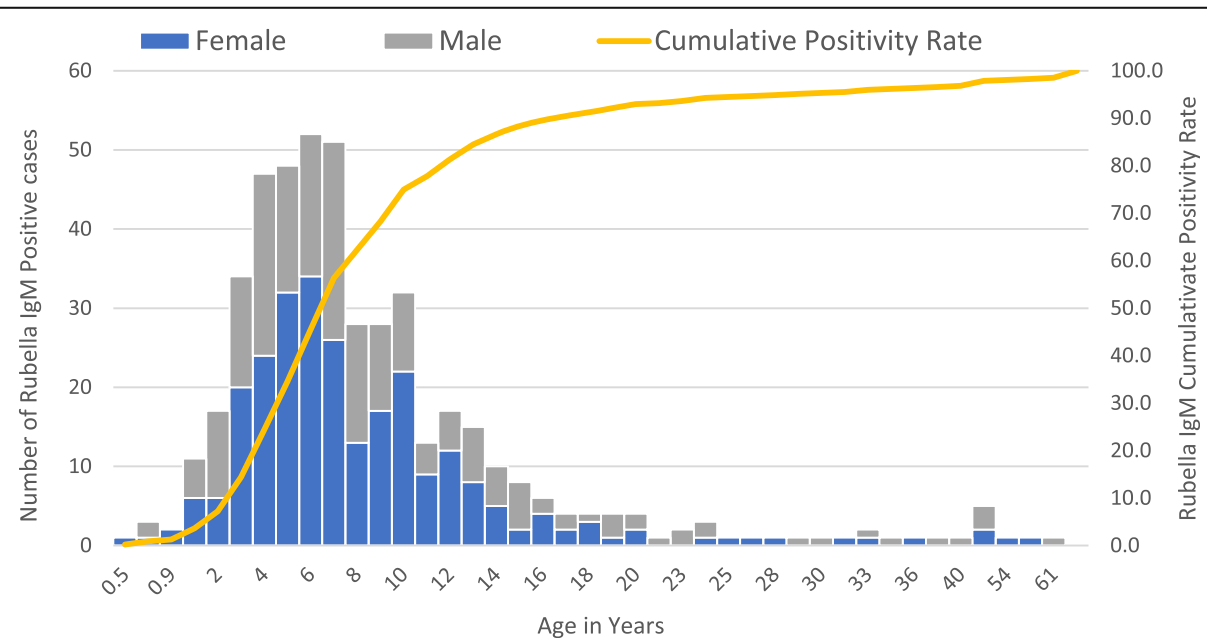

Fig. 1 Frequency of laboratory-confirmed rubella-specific immunoglobulin $\mathrm{M}$ antibody testing result by age and sex with a cumulative age distribution curve, 2017-2018, Liberia, $N=472$ (6 months to 61 years old) 


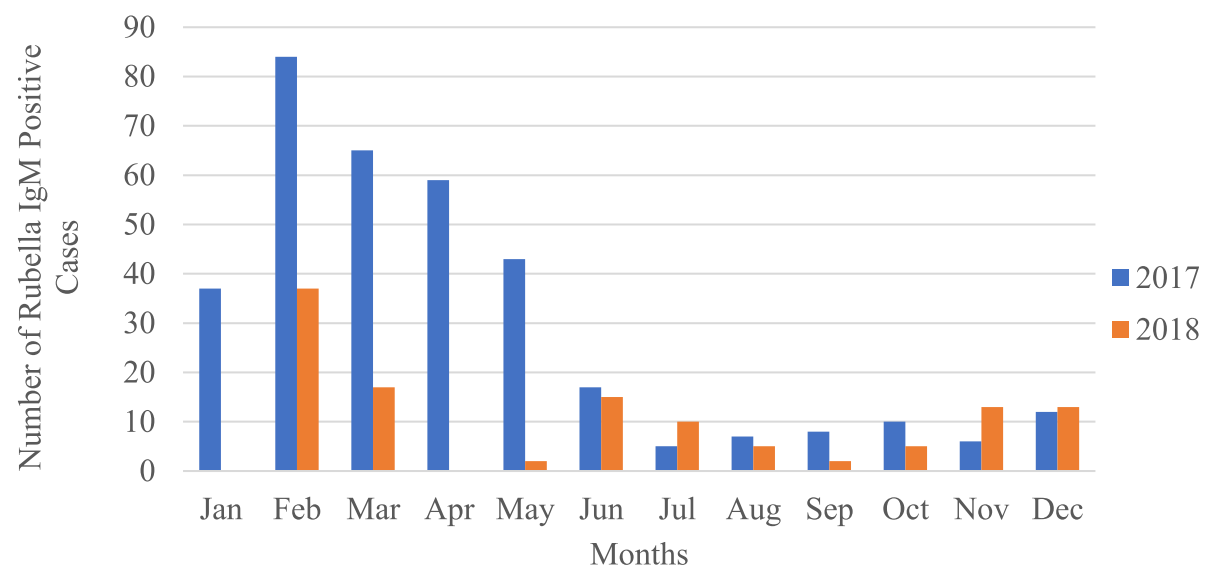

Fig. 2 Trends of rubella IgM positive cases by month, 2017-2018, Liberia, $N=472$ and cumulative positivity rate $=36 \%$

rubella in women of reproductive age contributed $3 \%$ of total confirmed rubella cases which are lower compared with our result. Rubella in women of childbearing age may suggest the possibility of rubella infection during pregnancy, which could potentially lead to CRS, occurs throughout the districts and remains largely undetected.

Although rubella infections were detected throughout the year, they were characterized by large peaks in the months from February to May, which corresponds with the dry and hot months in Liberia. A similar trend was observed in other countries in the tropical region, for instance, the highest number of rubella IgM positive cases were documented during the dry season in Ethiopia, Zimbabwe, and Niger [27, 30, 36, 37]. However, the reason why rubella infection increased to topmost during the dry and hot season was not clearly discussed. Some studies justified seasonal population migration from rural to urban areas was the main reason for the seasonal variation in rubella infections $[38,39]$. The case in Liberia was not clear and needs further study.

Our study has some limitations as we have depended on secondary data that was primarily collected to detect measles cases. As measles surveillance is mainly focused on detection and reporting of suspected-measles among

Table 2 Laboratory results for rubella-specific immunoglobulin M antibody testing of suspected measles cases by county, 20172018, Liberia

\begin{tabular}{|c|c|c|c|c|c|c|}
\hline \multirow[t]{2}{*}{ County } & \multirow{2}{*}{$\begin{array}{l}\text { asuspected } \\
\text { measles } \\
\text { cases }\end{array}$} & \multirow{2}{*}{$\begin{array}{l}\text { Rubella } \\
\text { lgM } \\
\text { tested }\end{array}$} & \multicolumn{4}{|c|}{ Rubella IgM result } \\
\hline & & & $\lg M+$ & $\lg M-$ & Indeterminate & Positivity \% \\
\hline Montserrado & 325 & 166 & 72 & 80 & 14 & 43 \\
\hline Lofa & 165 & 152 & 68 & 77 & 7 & 45 \\
\hline Margibi & 236 & 158 & 66 & 84 & 8 & 42 \\
\hline Bomi & 92 & 85 & 41 & 42 & 2 & 48 \\
\hline Bong & 163 & 86 & 33 & 51 & 2 & 38 \\
\hline Nimba & 219 & 98 & 29 & 63 & 6 & 30 \\
\hline Sinoe & 86 & 69 & 29 & 37 & 3 & 42 \\
\hline Grand Kru & 134 & 82 & 26 & 55 & 1 & 32 \\
\hline Grand Gedeh & 127 & 89 & 20 & 63 & 6 & 22 \\
\hline Maryland & 119 & 77 & 20 & 54 & 3 & 26 \\
\hline Grand Bassa & 118 & 55 & 19 & 32 & 4 & 35 \\
\hline Grand Cape Mount & 60 & 42 & 19 & 22 & 1 & 45 \\
\hline River Gee & 94 & 80 & 17 & 57 & 6 & 21 \\
\hline Gbarporlu & 29 & 25 & 7 & 18 & 0 & 28 \\
\hline Rivercess & 60 & 43 & 6 & 34 & 3 & 14 \\
\hline Total & 2027 & 1307 & 472 & 769 & 66 & 36 \\
\hline
\end{tabular}

${ }^{\mathrm{a}} \mathrm{Suspected}$ measles cases with known laboratory result, IgM Immunoglobulin $\mathrm{M}$ 


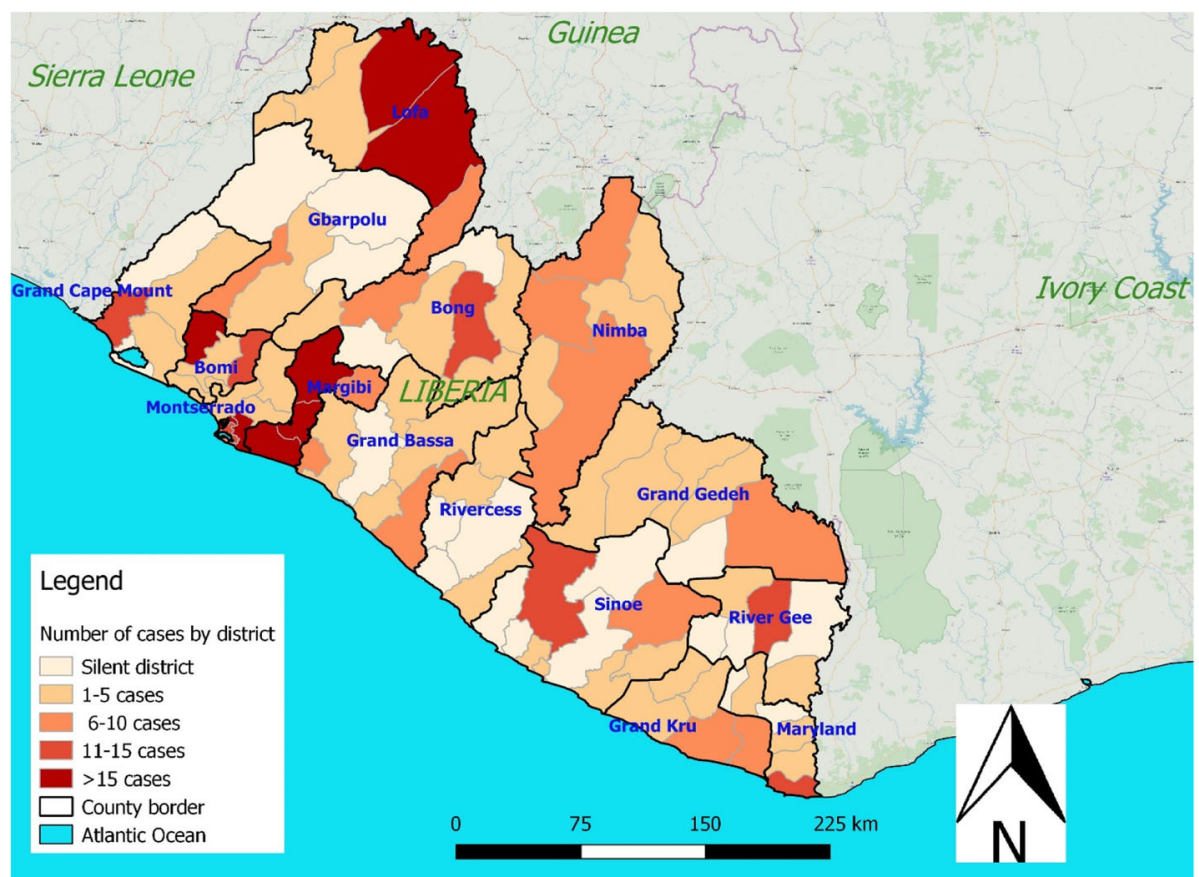

Fig. 3 Map showing the distribution of rubella IgM positive cases and its positivity rate by district, 2017-208, Liberia

children, mild rubella cases in adult or older age groups might be potentially underreported. Furthermore, the clinical manifestation of rubella cases may not meet suspected-measles case definition as $20-50 \%$ of rubella infections do not include a rash [40] and up to $50 \%$ of infections may be in-apparent [3]. Measles surveillance is less sensitive for rubella detection [17]. We also used only suspected measles cases with known laboratory result. Because of a shortage of the reagent, a significant number of measles suspected cases were not tested for both measles and rubella IgM in 2018. The system also relies mostly on health facilities and may have missed some community cases. Hence, the data we presented here might have represented small quota of possible rubella infections in Liberia.

\section{Conclusions}

This report provides a baseline and useful information on rubella epidemiology and transmission pattern in Liberia. Our finding demonstrated that rubella IgM positive cases had detected through the routine measles case-based surveillance system and widely circulating in Liberia. Rubella cases reported among all age groups including among infants under 1 year age and women of childbearing age. However, CRS has not detected and reported through the surveillance system. The ministry of the health of Liberia in collaboration with its partners should establish CRS surveillance according to WHO Guideline [41]. CRS sentinel surveillance needs to be established in selected health facilities mainly at maternal and child health facilities. Rubella IgM positive cases among women of childbearing age need to be further investigated and closely followed up for an outcome in case of pregnancy during infection. Similarly, rubella cases among infants in under one-year-old

Table 3 Annualized Rubella IgM positive cases incidence rate by county, 2017-2018, Liberia

\begin{tabular}{|c|c|c|c|}
\hline County & $\begin{array}{l}\text { Mid-Year } \\
\text { population }\end{array}$ & $\begin{array}{l}\text { Rubella IgM } \\
\text { positive cases }\end{array}$ & $\begin{array}{l}\text { Annualized incidence } \\
\text { rate per } 100,000 \\
\text { population }\end{array}$ \\
\hline Bomi & 91,593 & 41 & 22.4 \\
\hline Grand Kru & 60,152 & 26 & 4.5 \\
\hline Margibi & 232,918 & 66 & 3.4 \\
\hline Sinoe & 124,747 & 29 & 3.8 \\
\hline Lofa & 313,014 & 68 & 6.2 \\
\hline River Gee & 82,132 & 17 & 6.1 \\
\hline Grand Cape Mount & 153,386 & 19 & 21.6 \\
\hline Grand Gedeh & 164,360 & 20 & 10.9 \\
\hline Maryland & 176,733 & 20 & 14.2 \\
\hline Bong & 366,547 & 33 & 5.7 \\
\hline Grand Bassa & 253,001 & 19 & 2.3 \\
\hline Gbarporlu & 103,502 & 7 & 2.7 \\
\hline Rivercess & 88,758 & 6 & 10.3 \\
\hline Nimba & 542,289 & 29 & 3.4 \\
\hline Montserrado & $1,550,718$ & 72 & 11.6 \\
\hline Total & $4,303,851$ & 472 & 5.5 \\
\hline
\end{tabular}

aProjected from the 2008 population census [26] 
should be investigated for CRS. The introduction of a single dose RCV as measles-rubella (MR) in the existing routine immunization program is important to prevent rubella virus transmission and possible CRS and its public health consequence. Further study is also important to describe rubella susceptibility profile in school-aged girls and women of childbearing age in Liberia.

\section{Abbreviations}

BCG: Bacillus Calmette-Guérin vaccine; CRI: Congenital Rubella Illness; CRS: Congenital Rubella Syndrome; ELISA: Enzyme-Linked Immunosorbent Assay; EPI: Expanded Program on Immunization; IDSR: Integrated Diseases Surveillance and Response; IgM: Immunoglobulin M; IPV: Inactivated Polio Vaccine; NPHIL: National Public Health Institute of Liberia; OPV: Oral Polio Vaccine; QGIS: Quantum Geographic Information System; RCV: Rubella Containing Vaccine; WHO: World Health Organization

\section{Acknowledgments}

We would like to thank the NPHIL for allowing us to use measles surveillance data for this analysis. We would also like to thank WHO, UNICEF and Centers for Diseases Control and Prevention (CDC) for supporting the immunization and surveillance activity in Liberia. The Stop Transmission of Polio Program significantly supported detection, verification and investigation of vaccine preventable diseases including rubella and routine immunization program. Finally, we would like to thank health facilities, surveillance officers and clinicians for detecting and timely reporting surveillance data with blood specimens.

\section{Authors' contributions}

ABW cleaned, categorized and analyzed surveillance data, ABW interpreted the data and prepared manuscript, MSA helped data cleaning and analysis, prepared the map reviewed and supported preparation of the manuscript. TK supported the data analysis, RT, HK and JD contributed to the interpretation of the data, AB supported data analysis and discussion, JM, SA and TN participated in data interpretation and contributed on manuscript writing, GM, MK and JS helped manuscript writing, KY supported data cleaning and analysis, TNe contributed in data interpretation and manuscript writing, and MZG overseen the overall activity and reviewed the manuscript. All authors reviewed and approved the final version of the manuscript.

\section{Funding}

No budget allocated for these activities. Surveillance data were collected through routine surveillance. The surveillance stuffs who generated the data are a permanent staff of Ministry of Health of Liberia. The WHO provided technical support to the ministry of health and local health teams on the routine surveillance system. The opinions expressed by authors contributing to this article do not necessarily reflect the opinions of the WHO, Ministry of Health of Liberia and National Public Health Institute of Liberia.

\section{Availability of data and materials}

The datasets used to prepare this report are available at the National Public Health Institute of Liberia and can be obtained from corresponding author.

\section{Ethics approval and consent to participate}

This work is a retrospective surveillance data analysis that is part of routine disease monitoring activity. The data we presented here was collected through the routine surveillance system. Blood specimen and demographic information were collected based on national IDSR technical guideline for surveillance purpose [24]. Laboratory analysis was conducted aiming to detect measles and rubella cases as part of the routine activity. Permission was obtained from the National Public Health Institute of Liberia to analyze the secondary data. Name, pictures and any other information that discloses personal information of the patient was not included in this report. Hence, an ethical review was not sought and obtained for this work. Consent to participate in the study was not obtained as it is not applicable to this study.

\section{Consent for publication}

As our report does not include individual data, consent for publication is not applicable for this article.

\section{Competing interests}

The authors declare that they have no competing interests.

\section{Author details}

${ }^{1}$ World Health Organization Country office for Liberia, Monrovia, Liberia. ${ }^{2}$ Republic of Liberia Ministry of Health, Monrovia, Liberia. ${ }^{3}$ National Public Health Institute of Liberia, Monrovia, Liberia.

Received: 6 March 2019 Accepted: 11 September 2019

Published online: 18 September 2019

\section{References}

1. Rubing Chen, Suchetana Mukhopadhyay, Andres Merits, Bethany Bolling, Farooq Nasar, Lark L. Coffey, Ann Powers, Scott C. Weaver, Donald Smith PS and SS. Create one new unassigned family Matonaviridae to contain the genus Rubivirus, moved from the family Togaviridae 2018. 013S. rubing.chen@gmail.com. https://talk.ictvonline.org/files/ictv_official_ taxonomy updates_since the 8th_report/m/animal-ssrna-viruses/8087. Accessed 05 Sept 2019

2. World Health Organization. Rubella Fact Sheet. 2018, https://www.who.int/ news-room/fact-sheets/detail/rubella

3. Center for Disease Control And Prevention. Rubella Virus. In: Epidemiology and Prevention of Vaccine-Preventable Diseases. 13th ed. Atlanta; 2015. p. 325-40. https://www.cdc.gov/vaccines/pubs/pinkbook/ downloads/rubella.pdf. Accessed 15 Apr 2019.

4. Centers for Diseases Control and Prevention. Last reviewed For Healthcare Professionals. Centers for diseases control and prevention. 2019. https:// www.cdc.gov/rubella/hcp.html. Cited 2019 Feb 14

5. Khanal S, Bahl S, Sharifuzzaman M, Dhongde D, Pattamadilok S, Reef S, et al. Progress toward Rubella and congenital Rubella syndrome control —SouthEast Asia region, 2000-2016. Morb Mortal Wkly Rep. 2020:67(21):2016-20.

6. World Health Organization. Rubella vaccines: WHO position paper. Wkly Epidemiol Rec. 2011:(29):301-16 https://www.who.int/wer/2011/wer8629. pdf?ua=1. Accessed 15 Apr 2019.

7. World Health Organization. Congenital Rubella Syndrome. Geneva: World Health Organization; 2018. p. 1-16. https://www.who.int/immunization/monitoring_ surveillance/burden/vpd/WHO_SurveillanceVaccinePreventable_03_CRS_R2.pdf

8. FT Cutts EV. Modelling the incidence of congenital rubella syndrome in developing countries. Int J Epidemiol. 1999;28:1176-84.

9. Centers for Disease Control and Prevention. Measles and rubella fact sheett Ct Dis Control Prev. 2017; https://www.cdc.gov/globalhealth/measles/default.htm. Accessed 15 Apr 2019.

10. Cutts FT, Robertson SE, Samuel R. Control of rubella and congenital rubella syndrome (CRS) in developing countries, part 1: burden of disease from CRS. Bull World Health Organ. 1997;75(1):55-68.

11. World Health Organization. WHO-recommended standards for surveillance of selected vaccine-preventable diseases. Geneva: World Health Organization; 1999. p. 23-35. http://www.who.int/iris/handle/10665/64165

12. Lambert N, Strebel P, Orenstein W, Icenogle J, Poland GA. Rubella. Lancet. 2015;385(9984):2297-307.

13. Strebel P. Dabbagh A, Gacic-Dobo M, SE Reef SC. Progress toward control of Rubella and prevention of congenital Rubella syndrome - worldwide, 2009. MMWR. 2010;59(40):1307-10.

14. Strebel PM, Gacic-dobo M, Reef S, Cochi SL. Global use of Rubella vaccines, 1980 - 2009. J Infect Dis. 2011:204(Suppl 2):579-84.

15. World Health Organization. Measles and Rubella global update. Geneva: World Health Organization; 2018. https:/www.who.int/immunization/sage/ meetings/2018/october/SAGE_october_2018_measles_rubella_Dabbagh.pdf

16. Vanderende K, Gacic-dobo M, Diallo MS, Conklin LM, Wallace AS. Global routine vaccination coverage - 2017. MMWR. 2018;67(45):1261-4.

17. Grant GB, Reef SE, Patel M, Knapp JK, Dabbagh A. Progress in Rubella and congenital Rubella syndrome control and elimination - worldwide , 2000 - 2016. Morb Mortal Wkly Rep. 2020;66(45):1256-60.

18. Reef SE, Redd SB, Abernathy E, Zimmerman L, Icenogle JP. The epidemiological profile of Rubella and congenital Rubella syndrome in the United States, 1998 - 2004 : the evidence for absence of endemic transmission. Clin Infect Dis. 2006;43(Suppl 3):s116-32. 
19. Goodson JL, Masresha B, Dosseh A, Byabamazima C, Nshimirimana D, Cochi $\mathrm{S}$, et al. Rubella epidemiology in Africa in the Prevaccine era , 2002 - 2009. J Infect Dis. 2011;204(Suppl 1):S2015-225.

20. Luce R, Masresha BG, Katsande R, Fall A, Shibeshi ME. The Impact of Recent Rubella Vaccine Introduction in 5 Countries in The African Region. J Immunol Sci. 2018;2(16):108-12.

21. World Health Organization. Global measles and rubella strategic plan 20122020. Geneva: World Health Organization; 2012.

22. Liberia Ministry of Health. EPI Comprehensive Multi Year Plan (cMYP) 2016 -2020. Monrovia: Republic of Liberia M; 2016. http://www.nationalplanningcycles.org/ sites/default/files/planning_cycle_repository/liberia/liberia_cmyp_2016_2020.pdf

23. World Health Organization and United Nations Children's Emergency Fund. Liberia -WHO and UNICEF estimates of immunization coverage : 2017 revision. Geneva; 2018. https:/www.who.int/immunization/monitoring_surveillance/data/br.pdf. Accessed 15 Apr 2019.

24. Ministry Of Health Liberia. National Technical Guideline for integrated disease surveillance and response. Monrovia: WHO| Regional Office for Africa; 2016. http://www.afro.who.int/en/integrated-disease-surveillance/

25. World Health Organization Regional Office for Africa. African regional guidelines for Measles and Rubella surveillance. Brazzaville: WHO Regional Office for Africa; 2015.

26. Census H, Results F. Republic of Liberia 2008 population and housing census final results; 2009

27. Chimhuya S, Manangazira P, Mukaratirwa A, Nziramasanga P, Berejena C Shonhai A, et al. Trends of rubella incidence during a 5 -year period of case based surveillance in Zimbabwe. BMC Public Health. 2015;15:294):1-8.

28. Farra A, Pagonendji M, Manikariza A, Rawago D, Ouambita-mabo R, Guifara $\mathrm{G}$, et al. Epidemiology of primary rubella infection in the Central African Republic : data from measles surveillance, 2007 - 2014. BMC Infect Dis. 2016;16(505):1-6. https://doi.org/10.1186/s12879-016-1842-2.

29. Mitiku K, Bedada T, Masresha B, Kegne W, Nafo-Traoré F, Tesfaye N, Beyene B. The epidemiology of Rubella disease in Ethiopia : data from the measles case-based surveillance system. J Infect Dis. 2011;204(Suppl 1):239-42.

30. Getahun M, Beyene B, Gallagher K, Ademe A, Teshome B, Tefera M, et al. Epidemiology of rubella virus cases in the pre-vaccination era of Ethiopia 2009 - 2015. BMC Public Health. 2016;16(1168):1-7.

31. Umeh CA, Onyi SC. Case based rubella surveillance in Abia state, south EastNigeria, 2007-2011. PeerJ. 2014;2:e580.

32. Mengouo MN, Ndze VN, Baonga F, Kobela M, Wiysonge CS. Epidemiology of rubella infection in Cameroon : a 7-year experience of measles and rubella case-based surveillance, 2008 - 2014. BMJ. 2017;7:e012959.

33. Gomwalk NE. AAA. Prevalence of Rubella antibodies on the African continent. Rev Infect Dis. 1989;11(1):116-21.

34. Rubella FAKL-E. World impact. Rev Infect Dis. 1985;7(Supplement 1):s29-36.

35. Pukuta E, Waku-kouomou D, Abernathy E, lllunga BK, Obama R, Mondonge V, et al. Genotypes of Rubella virus and the epidemiology of Rubella infections in the Democratic Republic of the Congo , 2004 - 2013. J Med Virol. 2017;88(10):1677-84.

36. Mitiku K, Bedada T, Masresha B, Kegne W, Nafo-Traoré F, Tesfaye N, Beyene B. The epidemiology of Rubella disease in Ethiopia : data from the measles case-based surveillance system. J Infect Dis. 2011:1899(Suppl 1):239-42.

37. Fatiregun AA, Fagbamigbe AF, Adebowale AS. Epidemiology of rubella disease in south-west nigeria : trends and projection from measles casebased surveillance data Epidemiology of rubella disease in south-west Nigeria : trends and projection from measles case-based surveillance data. South Afr J Infect Dis. 2014;29(2):60-4.

38. Wesolowski A, Metcalf CJE, Eagle N, Kombich J, Grenfell BT. Quantifying seasonal population fluxes driving rubella transmission dynamics using mobile phone data. PNAS. 2015;112(35):11114-9.

39. Bharti N, Tatem AJ, Ferrari MJ, Grais RF, Dijbo A. BTG. Explaining seasona fluctuations of measles in Niger using nighttime lights imagery. Science. 2014:334(6061):1424-7.

40. Lanzieri T, Redd S, Abernathy E, Icenogle J. Rubella. In: VPD surveillance Manua. Atlanta: Centers for Disease Control and Prevention; 2011. p. 1-12.

41. World Health Organization. Guidelines for surveillance of congenital rubella syndrome and rubella. Geneva: World Health Organization; 1999. p. 1-41. https://apps.who.int/iris/bitstream/handle/10665/66104/WHO-VandB-99.22eng.pdf? sequence $=1$

\section{Publisher's Note}

Springer Nature remains neutral with regard to jurisdictional claims in published maps and institutional affiliations.

\section{Ready to submit your research? Choose BMC and benefit from:}

- fast, convenient online submission

- thorough peer review by experienced researchers in your field

- rapid publication on acceptance

- support for research data, including large and complex data types

- gold Open Access which fosters wider collaboration and increased citations

- maximum visibility for your research: over $100 \mathrm{M}$ website views per year

At BMC, research is always in progress.

Learn more biomedcentral.com/submissions 